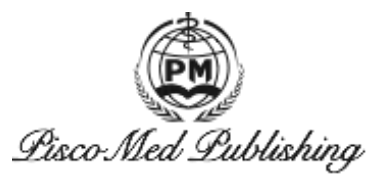

Review Article

\title{
Analysis of civil engineering construction technology and its future development
}

Juntao Mao

Jiangsu Testing Center for Quality of Construction Engineering Co., Ltd. No. 107 Hongshan Road, Xuanwu District, Nanjing, Jiangsu Province 210028, China; maojt_tandy@foxmail.com

\begin{abstract}
With the rapid development of the current economic society, civil engineering construction technology has made great progress as well, which has promoted the development of the entire construction industry and is conducive to continuously improving people's living conditions. Therefore, it is quite important to explore and study this topic. This paper analyzes and discusses the current development situation and future prospects of civil engineering construction technology, aiming to promote its good development and provide more comfortable and pleasant living environment for people.
\end{abstract}

Keywords: Civil engineering; construction technology; future development

Received: November 21, 2019 Accepted: December 16, 2019 Published: December 20, 2019

\section{Introduction}

The rapid development of economic society and high technology has reformed various industries in the economic development, including the construction industry. New technologies have driven the development of civil engineering construction technology in high speed, the research on which will contribute to the high-quality development of the entire construction industry. As civil engineering construction technology greatly affects the quality and safety of buildings, the research on it is of critical importance in order to ensure the construction quality and safety. With the increasing difficulty of current construction conditions and the continuous development of new technologies and materials, civil engineering construction technology needs to adapt to changes in the external environment so as to develop well. The author has carried out systematic research on the current civil engineering construction technology and the future development trend.

\section{The development history of civil engineering construction technology}

The development history of civil engineering construction technology can trace back to the appearance of human beings. Civil engineering construction technology had been developing slowly from the ancient Stone Age to the Renaissance of the Middle Ages. After at least 2,000 years of development, due to the backwardness of production technology, civil engineering construction technology was still primitive and didn't achieve a qualitative leap. After the Renaissance of the Middle Ages, with the rapid development of natural science, the long-term development of civil engineering construction 
technology had been promoted. At present, civil engineering construction technology, as a large-scale comprehensive discipline, is becoming more and more detailed with numerous branches, including construction engineering, bridge engineering, hydraulic engineering, municipal engineering, port engineering, highway engineering. At the same time, the development of civil engineering construction technology is as rapid as that of the current economy and society. China's civil engineering construction technology has made remarkable achievements since the reform and opening up. Some projects with world influence, such as Shanghai World Financial Center, Water Cube and Three Gorges Project, are sufficient to show that China's construction technology has reached the world's leading level.

\section{The main tasks of the current civil engineering construction technology}

It is widely known that the outstanding characteristics of civil engineering construction technology are strong sense of theory and practice, and rapid development. The construction process comprises many projects, such as earthwork, concrete structure, house decoration, and brick construction. Generally speaking, civil engineering construction is the theoretical method researched on buildings, that is, constructing the most comfortable and economical buildings with the least resource consumption, so as to meet the living needs of human beings. Therefore, from this aspect, it can be seen that civil engineering construction technology will be a discipline with particularly strong practicality. The development direction of construction will determine that of civil engineering construction technology. Development of economy and society not only promotes but also requires the high-speed development of the construction industry. Meanwhile, the continuous emergence of new technologies and new materials supports the development of civil engineering construction technology as well. It can be said that civil engineering construction technology will play a decisive role in the future development of the construction industry.

Therefore, in order to promote the high-quality development of the construction industry, it is necessary to strengthen the improvement of civil engineering construction technology. Although from the current situation, more construction enterprises have reached a reasonably good level in the civil engineering construction technology, higher technology is required for the current buildings with unique shapes, complex structures and large spans, which will greatly promote the new development of civil engineering construction technology. At present, in the case of the basic engineering and the construction treatment of some engineering foundations, engineering construction technologies emerge, for example diaphragm wall, large diameter deep cobalt hole grouting, underpinning technology and grouting method. In the field of concrete engineering, concrete pumping and mixing technologies have been deeply developed; fiber concrete technology has been vigorously promoted; some high-performance concrete has been used; at the same time, the technology of prestressed concrete has been improved in a wider range and achieved a major breakthrough in the field of cable-membrane structures. Steel structure construction technology has been developed, which can be adopted by most construction enterprises. Light steel structure technology has a wide range of applications, and the application prospect of prestressed steel structure in the market is becoming brighter. Synchronous development and progress have also been achieved in the fields of the underground waterproofing technology, modern house decoration technology and roof waterproofing technology, etc.

With the gradual acceleration of China's urbanization construction, the organization and technology of construction have gradually become prominent, and the technical level of civil engineering construction has been continuously developed. In the first five-year plan after the founding of new China, the national construction administrative department organized and compiled more standardized technical work for many important engineering projects. After the reform and opening up, with the high development of computer and Internet technologies, especially the integration of current informatization with various industries, the technology level of construction projects has achieved rapid development, and the construction organization design technology and project management level of construction projects have been significantly 
improved. Thus we can see that the coordinated development of many fields such as social economy, science and technology, has greatly promoted the development of construction technology and civil engineering technology, and the high-quality development of the construction industry, whose future development direction will be directly determined. The present continuous improvement of the scientific and technological level of the whole society has definitely promoted the development of construction technology and economy and society in an efficient way. People's material living standard has gradually been improved with the demand for high-quality living getting higher and higher. Under this social development background, prefabricated buildings have received attention from all aspects of the society.

\section{Development of prefabricated buildings}

Prefabricated buildings, in short, are buildings assembled, whose construction materials needed in the construction process are produced in related factories and directly transported to the construction site when in need. Construction enterprises and technicians organize corresponding processing activities according to the construction materials to complete the assembling. It is observed that prefabricated buildings are more and more recognized by the society due to their characteristics of energy conservation, environmental protection and high efficiency. At the same time, with the development of society, traditional buildings have exposed more problems and deficiencies. Take the houses of everyday life as an example. There are many problems requiring attention to be paid. While people's living demands are improving, the houses still lack selectivity and diversity, without meeting people's living demands. At present, commercial houses built by well-known real estate developers all over the country are far from satisfying people's personalized living needs because of their own shortcomings in function, design and construction.

Prefabricated buildings are more flexible in division with more large space. Users can divide rooms based on their own actual living conditions, which can effectively meet personalized living demands. In this way, the residents can determine the construction, so as to achieve different space designs, realize the personalized demands of people easily, avoid the defects of single functionality of traditional buildings, realize multifunctional designs of the houses, and improve the living quality of people. The self-weight of fabricated buildings is much lighter than that of traditional buildings. Therefore, the foundation can be simplified which will shorten the construction period and reduce the number of construction personnel required, with the environment of the construction site becoming better, the discharge amount of waste water and waste residue reduced, and disturbance to the environment reduced at the same time. Meanwhile, due to the relatively small amount of bulk materials, the construction cost can be cut down. It is clear that prefabricated buildings will win high recognition from all sides of society in the future and greatly meet people's personalized living demands.

\section{Research on the future development trend of civil engineering construction technology}

\subsection{Closely combine civil construction technology with the development of science and technology}

In order to maximize the profits of construction enterprises, civil engineering construction technology needs to be closely combined with advanced science and technology. Only in this way can the construction cost be effectively reduced. Building cost of projects is an important parameter in the process of project construction which can only be reduced by advanced construction technology, that is reducing the cost of mechanical equipment, labor and materials in the construction process and achieving the mechanization, automation and intelligence level of project construction. Civil engineering construction technology is guided by advanced science and technology to realize all-round development and continuously improve construction efficiency.

\subsection{Research on automation trend of civil engineering construction technology}

In the future, the key to civil engineering construction is automation, which is also the key development direction of future engineering construction. In order to realize automatic construction, it is necessary to reform the traditional construction method, strengthen 
the standardization of construction technology, adopt the construction method of assembly line, and continuously improve the construction production efficiency.

\subsection{Pay more attention to energy conservation and environmental protection}

The future development trend of civil engineering construction technology is that more attention being paid to environmental protection and resource conservation. Civil engineering is a way for human beings to transform nature, which will cause certain damage to it. Therefore, how to balance the relationship between civil engineering construction and environmental protection and resource conservation is an important issue to be considered in promoting the sustainable development of human society. Only by paying more attention to energy conservation and environmental protection in civil engineering construction technology can civil engineering construction technology win more development space.

\section{Conclusion}

Currently, civil engineering construction technology is developing towards informatization, intelligence and intensification, which is due to the continuous progress of science and technology around the world. With the continuous emergence of new technologies and materials, new civil engineering construction technologies will continue to emerge, and be applied and promoted practically. At that time, it will effectively promote the technical development level of the construction industry, thus promoting the continuous improvement of people's quality of living and the high-quality development of the entire construction field.

\section{References}

1. Wang LJ. Study on the influence of safety industry research results on the quality of civil engineering [J]. Journal of Taiyuan University (natural science edition) 2019; 37(04): 5-8.

2. Zhang HJ. Analysis of crack treatment in civil engineering construction [J]. Jiancai Yu Zhuangshi 2019; (35): 41-42.

3. Guo S. Research on the quality control method of civil engineering management and construction process [J]. Jiancai Yu Zhuangshi 2019; (35): 207-208. 